\title{
High Trait Anger, Interpersonal Context, and the Recognition of Anger Problems
}

\author{
Raul J. Alcazar-Olan, PhD \\ Universidad Iberoamericana Puebla, México \\ Laura Hernandez Guzman, PhD \\ Universidad Nacional Autónoma de México \\ Veronica Reyes Perez, PhD \\ Universidad de Guanajuato, Campus León, México \\ Claudia Gonzalez Fragoso, PhD \\ David Jimenez Rodriguez, PhD \\ Universidad Autónoma del Estado de Hidalgo, México
}

doi: 10.19044/esj.2017.v13n26p42 URL:http://dx.doi.org/10.19044/esj.2017.v13n26p42

\begin{abstract}
Background: High trait anger is usually destructive for individuals and their relationships. This proneness to anger is reflected in frequent angry feelings, for longer periods of time, and with higher levels of physical arousal and negative expressions (e.g., insulting or arguing with others). Unfortunately, not all individuals with high trait anger recognize the problem. Objective: This research assessed the contribution of the interpersonal context (e.g., family members, friends, and boyfriend/girlfriend) to recognize anger problems. Methods: We recruited 192 individuals with high trait anger who completed questionnaires about 1) recognition of anger problems, 2) how they are perceived by others in terms of anger (i.e., "being irascible"), and 3) if they care about what others think about their anger. Research Design: Cross-sectional. Results: Individuals who recognized their anger problems perceived they have received more messages of "You are very irascible" from their social contexts, while those who do not recognize anger problems, have received these messages less often. Moreover, the higher the extent to which the individuals care about what other people think or say about their anger (i.e., higher importance attached to messages from others), the more it contributed to a higher recognition of anger problems. In addition, a lower importance attached to such messages was related to a lower recognition of such problems. Recognition of anger problems was higher in participants who had a boyfriend/girlfriend (versus those who did not have one), and in female (versus male) participants.
\end{abstract}


Keywords: Anger; Anger problems; Interpersonal context; Recognition; Trait anger

\section{Introduction}

Some individuals with high trait anger recognize their anger problems, while others do not. High trait anger is the tendency to get angry easily across time and situations. Since it is considered a personality characteristic, trait anger reflects a chronic, internal, and quick disposition to feel anger (Brotman, Kircanski, Stringaris, Pine, \& Leibenluft, 2017; Kuppens, Mechelen, \& Rijmen, 2008; Spielberger, 1999; Wilkowski \& Robinson, 2010). High trait anger can be seen as generalized anger (Deffenbacher, 1993) because it represents a widespread pattern of angry reactions in a variety of situations. Thus, high trait anger implies a particular, idiosyncratic tendency to interpret others' behaviors as badly intended and extremely unfair, attaching to the wrongdoer denigrating labels (e.g., "S/he is an idiot!"), which results in frequent angry feelings (Deffenbacher, 2009; Smith, Haynes, Lazarus, \& Pope, 1993).

Individuals with high trait anger consistently have characteristics that individuals with low trait anger have in a significantly lesser degree (Deffenbacher et al., 1996; Deffenbacher, Richards, Filetti, \& Lynch, 2005; Quinn, Rollock, \& Vrana, 2014; Wang, Yang, Yang, Wang, \& Lei, 2017). For example, compared to people with low trait anger, those with high trait anger: a) become more easily angered; b) experience anger with more intensity, i.e., higher levels of physical arousal; c) express their anger in less constructive ways; d) experience more anger suppression, e.g., harboring grudges and "boiling" in the inside but not showing it; and e) experience negative, severe anger consequences. Given its problematic nature, high trait anger coexists with mental disorders (Fernandez \& Johnson, 2016; Owen, 2011). For instance, unlike people with low trait anger, those with high trait anger experience more Axis I and Axis II disorders, indicating higher comorbidity (Kassinove \& Tafrate, 2006; McDermut, Fuller, DiGiuseppe, Chelminski, \& Zimmerman, 2009).

Although high trait anger is associated with negative correlates in a variety of aspects (Deffenbacher et al., 1996; Kassinove \&Tafrate, 2006; McDermut et al., 2009; Wang et al., 2017), not all individuals recognize it. They actually experience problems, but from their perspective, they do not have anger problems (Deffenbacher, Filetti, Richards, Lynch, \& Oetting, 2003; Deffenbacher, Lynch, Filetti, Dahlen, \& Oetting, 2003). The lack of recognition is unfortunate because the recognition of a problem is a necessary step if a person wants to change (Prochaska \& Prochaska, 1999). A common previous step to solve a problem is by accepting that a problem 
exists (Miller \& Rollnick, 2013; Prochaska \& Prochaska, 1999). In particular, an impediment to the success of anger management is the lack of readiness to change (Deffenbacher, 2009; Howells \& Day, 2003).

Some studies have distinguished the characteristics of individuals who do and do not recognize anger problems. Compared to those who do not recognize them, those who do reported more aggression, anger suppression and harboring grudges, and fewer thoughts of self-control and attempts to control their angry behavior and feelings (Alcázar, Deffenbacher, Hernández, \& Jurado, 2015; Alcázar, Deffenbacher, Hernández, \& Wilson, 2011; Deffenbacher, Filetti, et al., 2003). The most consistent finding (so far) is that people who recognize the problem experience higher trait anger than those who do not recognize it (Alcázar, Deffenbacher, Hernández, et al., 2011, Alcázar, Deffenbacher, et al., 2015; Deffenbacher, Filetti, et al., 2003). Hence, trait anger was included in the present study to compare it with other variables.

Although previous research has focused on individual variables (i.e., trait anger and anger expression) with regard to the recognition of anger problems, interpersonal variables have not been explored. Nevertheless, anger is an interpersonal emotion. The interpersonal context is the site where anger emerges, given that most anger situations include the person involved and another human being (Alcázar, Jiménez, Mena, Ponce de León, \& Gutiérrez, 2015; Averill, 1983). Moreover, contexts of frequent contact (e.g., family members or boyfriend/girlfriend) harbor many anger episodes because this emotion usually emerges with loved ones (Alcázar, Jiménez, et al., 2015; Averill, 1983). Consequently, it is valid to assume that other individuals in the social context notice when the person is angry. Due to the fact that the interaction with significant others is usually frequent, important, and relatively permanent, others may play a role in recognizing anger problems.

The interpersonal dimension has not been deeply studied in the recognition of anger problems. This line of research might be promising to better understand the lack of recognition. For example, help-seeking in anger problems is often instigated by significant others, while help-seeking in other emotions (e.g., fear or sadness) may be self-initiated, or concerned others seek help on behalf of the person (Howells \& Day, 2003). Therefore, the social context may have an impact on the recognition of anger problems. This research explored this possibility by asking angry individuals how they are perceived by others in terms of anger. In particular, we expected that individuals who recognize their anger problems perceive they have received more often messages of "You are a very irascible person" from their social contexts, while those who do not recognize them have received these messages less often (Hypothesis 1). 
Assuming that significant others consider the individual as an angry, hotheaded person, this fact could be relevant, but may not be enough to recognize the problem. Probably, the recognition also depends on the importance that the individual attaches to messages from other people. For instance, some individuals might think: "What my friends think or say about my anger, is important to me" while others might not attach importance to it. This research examined the association between recognizing anger problems, and the importance that participants attach to what others think or say about the individuals' anger. In particular, we expect that a higher importance toward others' opinions contributes to the recognition of anger problems, and a lower importance attached to opinions from others relates to a lower recognition (Hypothesis 2).

Because Hypotheses 1 and 2 are of interpersonal nature, the frequency of social contact might be related to the frequency of the messages that participants receive from others. Individuals with more social contact may receive more messages (i.e., more feedback) from the others about their anger reactions. As a result, higher social contact may lead to recognition, and lower contact to lack of recognition. Thus, the frequency of contact may determine the recognition, not the accuracy or relevance of the message (i.e., the extent to which the message is both, important and true). To explore if frequent contact impacts the results, we also assessed the involvement between the participants and their social contexts; for example, the frequency and time they spend together.

Usually, men and women are similar in terms of anger experience and expression (Archer, 2004; Bartz, Blume, \& Rose, 1996; Deffenbacher et al., 1996). Few studies have analyzed gender in the recognition of anger problems (Alcázar, Deffenbacher, Hernández, et al., 2011; Alcázar, Deffenbacher, et al., 2015), showing no gender effects. Gender was included in this research as a demographic variable, without specific predictions.

In summary, this study assessed the contribution of these variables in the recognition of anger problems: 1) the propensity to experience anger (i.e., trait anger); 2) the frequency in which the individuals perceive they have received messages from their social contexts concerning the extent to which they are irascible people; 3 ) the degree to which the participants care about what significant others think or say about their anger (importance attached to others' messages); 4) the frequency of contact between the individuals and significant others; and 5) gender.

\section{Method \\ Participants}

The initial pool of participants consisted of 843 university students (434 male and 409 female), $M$ age $=20.17(S D=1.77)$. Students belonged to 
34 different majors. The highest number of participants $(9.8 \%)$ were from Industrial Engineering, and the participants from other majors were below 9.6\%. In terms of religion, $77 \%$ were Catholic, $6.6 \%$ belonged to other religions, and $16.4 \%$ did not report a religious preference. This pool of participants was necessary to find people with high trait anger. Usually, individuals with high trait anger are identified by statistical methods (explained in the next paragraph), and they represent approximately $25 \%$ of the population.

From the pool of participants, we recruited individuals with high trait anger ( $n=220 ; 100$ male and 120 female), which was the main inclusion criteria. Based on traditional practices on detection of problematic anger (DiGiuseppe \& Tafrate, 2003), high trait anger was operationally defined as scoring in the upper quartile (score > 24) on the Trait Anger Scale (see Instruments) of the current sample.

The examination of the sample showed that $12.73 \%$ of the participants did not have siblings. Given the acceptable sample size, participants with no siblings were eliminated to keep those with a wider and significant social context. As a result, the final sample had 192 participants (90 male and 102 female) with high trait anger. From these participants, 50\% lived with their mother (i.e., they answered yes to the question "Do you live with your mother in the same house?"), and 39.1\% lived with their father (i.e., they answered yes to the question "Do you live with your father in the same house?"). In addition, some participants ( 37 male and 52 female) had a boyfriend/girlfriend.

\section{Measures}

Involvement with Significant Others. These questions measured the frequency and extent of involvement between the participants and their social contexts. Two independent questions referred to the people with whom they live. In particular, "Currently, do you live with your mother in the same house?", and we used the same format to ask about the father. Participants chose yes or no as an answer to each question. Regarding siblings, we asked "How many years have you lived with your siblings in the same house?", and the answer choices ranged from 1 (I have never lived with my siblings) to 7 (between 26 and 30 years). Three questions were about frequency; for example, "Generally, how often do you and your mother talk or have conversations?" We used the same structure to ask about the frequency of conversations with the father and siblings. Answer choices ranged from 1 (never) to 5 (always).

Concerning friends, we asked "When you are with your friends, how much time do you generally spend with them?" Answer choices ranged from 1 (less than an hour) to 6 (more than eight hours). We also asked whether 
the participant had a boyfriend/girlfriend (yes or no), clarifying this term as referred to "A person you love and to whom you are committed." The people who said yes responded three additional questions: (a) the number of months the relationship has lasted; (b) the number of hours that most of the time they spend together, with answer choices from 1 (less than an hour) to 6 (more than eight hours); and (c) the frequency of their encounters including chat, skype or other electronic means, with answer choices from 1 (once every two or three months) to 5 (5-7 times per week or more).

Trait Anger Scale. The 10-item scale measures the tendency to get angry across time and situations (Spielberger, 1999). Items are descriptions (e.g., "I am a hotheaded person") of how the respondent feels in general. Answer choices range from 1 (almost never) to 4 (almost always). The Mexican version of the Trait Anger Scale has construct validity and acceptable reliability, $\alpha=.83$ (Alcázar, Deffenbacher, \& Byrne, 2011).

Recognition Scale. To assess the recognition of anger problems, we used the Stages of Change Readiness and Treatment Eagerness Scale (SOCRATES). The scale was originally created to assess drinkers' motivation to change (Miller \& Tonigan, 1996), and it has three factors/subscales: ambivalence (i.e., The individual wonders if s/he has a problem), recognition (i.e., The individual accepts s/he has a problem), and taking steps (i.e., The person is taking action to solve the problem).

The SOCRATES was modified (Alcázar, Deffenbacher, Hernández, et al., 2011) to use it with anger issues. Words like "drinking", "alcohol," and "drugs" were replaced by the phrase "anger problems." For example, the item "My drinking is causing a lot of harm" was reworded to "My anger problems are causing a lot of harm." The SOCRATES applied to problematic anger replicates the original three-factor structure found in drinking problems (Alcázar, Deffenbacher, Hernández, et al., 2011), including a recognition factor $(\alpha=.76-.81$, current $=.83)$, suggesting construct validity to assess recognition of anger problems. Items of recognition are: (a) "I need help to keep from going back to the same problems because of my anger"; (b) "My anger problems are causing a lot of harm"; (c) "I have serious problems because of my anger"; and (d) "If I do not do something soon to solve my anger problems, they will get worse." Answer choices were: 1 (strongly disagree), 2 (disagree), 3 (undecided), 4 (agree), and 5 (strongly agree), indicating how the item applied to the person. The total score of the four items was an index of the recognition of anger problems. Higher scores indicate higher recognition.

Perceptions about Social Context. We asked participants their opinion concerning their perception about the frequency they are told by other individuals that they are irascible. We used seven items; for example, "My mother tells me that I am a very irascible person." Answer choices 
were: 1 (She has never told me), 2 (She has almost never told me), 3 (She has sometimes told me), 4 (She has frequently told me), and 5 (She has always told me). The same item structure was used to inquire about father, siblings, friends, professors, boyfriend/girlfriend, and finally, about people in general. Construct validity of this (and the following scale) is below.

Importance of Others' Opinions. Participants responded to "How much do you care about the following?" Then, the items appeared; for example, "What my father thinks or says about my anger." Answer choices were: 1 (I do not care), 2 (I care a little), 3 (I care more or less), 4 (I care much), and 5 (I care very much). The same item structure was used to inquire about mother, siblings, friends, professors, boyfriend/girlfriend, and people in general.

The two scales described above involved interpersonal aspects and were created for this research. Therefore, the validity was unknown and had to be examined. Exploratory factor analysis (EFA) in the current sample $(n=$ 192, principal axis factoring and promax rotation) with items of both scales revealed three clear factors -without dual loadings- accounting for $62.87 \%$ of the variance. (Items about boyfriend/girlfriend were not entered in the EFA because only $46.4 \%$ of the sample had one. Consequently, these items were analyzed separately.) The resulting factors showed anger interpersonal aspects. Factor 1 (three items) was about the importance of others' opinions (i.e., mother, father, and siblings) in relation to one's anger, with loadings between .76 and .97, $\alpha=.89$. Based on its content, this is a measure about the importance attached to the family context. Factor 2 (six items) tapped the perceptions about the social context; that is, the participants' perceptions about receiving the message "You are very irascible," with loadings between .47 and $.72, \alpha=.75$. Factor 3 (3 items) assessed the importance of distal context (i.e., people in general, friends and professors), with loadings between .70 and $.83, \alpha=.80$. (The loadings for each item are available upon request.) Based on the results of the EFA, we considered three aggregated measures for data analysis: Importance of family context (mother, father, and siblings), Perceptions about others, and Importance of distal context (people in general, friends and professors).

\section{Procedure}

Research assistants administered the questionnaires during class hours to groups of 15-20 students. Instructors were present at least during the reading of the instructions. It was clarified that the study was anonymous and voluntary, and that participants could decline to answer. No student refused to participate. This research was approved by institutional review processes. Every year, research projects go through these processes in order to be approved or rejected by the Institution. 


\section{Results \\ Correlation Analyses}

Higher scores in the recognition of anger problems were related to higher trait anger (Table 1). Higher recognition was also related to higher frequency in which the participants perceive messages (i.e., "You are very irascible") from their social contexts, and related to the importance they attach to messages from family and distal contexts. Moreover, higher recognition of anger problems was associated with being a woman (not a man), and having a boyfriend/girlfriend (versus having none). Regarding individuals with a boyfriend/girlfriend, recognition of anger problems was related to the frequency that participants receive the message "You are very irascible" from the boyfriend/girlfriend $(r=.24, p<.05)$, and related to the importance that individuals attach to the messages from the boyfriend/girlfriend $(r=.28, p<.01)$. These variables were further analyzed through regressions to examine their contributions in the recognition of anger problems.

The recognition of anger problems had negligible correlations with the frequency of conversations between the participants and the mother, father, and siblings, and with the amount of time spent with friends (Table 1). Recognition was not associated with living with the mother or father or the years living with siblings. Considering only the participants who had a boyfriend/girlfriend, the recognition of anger problems did not correlate with the number of hours they usually spend together $(r=-.08, n s)$, the number of months the relationship has lasted $(r=.08, n s)$, nor with the frequency of contact between them $(r=.04, n s)$. The negligible correlations suggest the frequency of contact with others (as perceived by the participants) does not explain the recognition of anger problems.

\section{Regression Analyses}

Collinearity statistics (i.e., tolerance and variance inflation factor) were all within acceptable limits (i.e., above 0.1 and below 10.0, respectively), according to Hair, Anderson, Tathan, and Black (1999) criteria, indicating it is appropriate to assess predictor variables in a regression model. For the continuous variables, $Z$-scores were used.

A Four Step hierarchical multiple regression was conducted with recognition of anger problems as the dependent variable. Gender and having a boyfriend/girlfriend (yes-no) were entered at Step one for controlling their effects. Step two included trait anger because this variable has been previously associated with the recognition of anger problems. Step three had the perceptions concerning the social context, a variable not previously tested. 
Step four considered the importance attached to the social context. Since we identified two contexts (i.e., family and distal), we assessed each one separately. In particular, Steps one to three were kept as described above. Step four (a) included the family context, and Step four (b) the distal context.

As a result of the hierarchical multiple regression, all the predictor variables contributed significantly to the recognition of anger problems in the four Steps (Table 2). The exception was gender, which contributed to the model that considered the family context (women recognize it more than men), but it did not contribute to the model of distal context.

Table 1 .

Correlations between the Recognition of Anger Problems and other variables

\begin{tabular}{|c|c|c|c|c|c|c|c|c|c|c|c|c|c|c|c|}
\hline Variables & 1 & 2 & 3 & 4 & 5 & 6 & 7 & 8 & 9 & 10 & 11 & 12 & 13 & $M$ & $S D$ \\
\hline $\begin{array}{c}\text { Recognition } \\
\text { of anger } \\
\text { problems }\end{array}$ & .28 & .26 & .16 & .24 & .22 & .11 & .02 & -.05 & .04 & -.12 & -.04 & -.07 & -.30 & 10.98 & 4.38 \\
\hline 1, Trait ange & & .32 & -.10 & .04 & .15 & -.06 & -.01 & -.02 & .05 & .00 & -.04 & -.01 & -.01 & 29.12 & 3.59 \\
\hline 2 , Perceptions a & out ot & & .04 & -.09 & .03 & .03 & .03 & .00 & .05 & .01 & -.01 & .01 & .05 & 18.03 & 4.36 \\
\hline \multicolumn{4}{|c|}{ 3, Importance of family context } & .47 & -.07 & .10 & .08 & .00 & .06 & .12 & .11 & .00 & -.01 & 9.91 & 3.67 \\
\hline \multicolumn{4}{|c|}{ 4, Importance of distal context } & & .23 & .15 & .08 & .17 & -.04 & .00 & -.01 & -.15 & -.12 & 7.52 & 3.08 \\
\hline \multicolumn{4}{|l|}{5 , Gender } & & & .02 & .12 & .09 & .15 & -.17 & .08 & -.09 & -.10 & -- & -- \\
\hline \multicolumn{4}{|c|}{ 6, Living with mother (yes-no) } & & & & .65 & -.16 & .00 & .01 & .01 & -.12 & -.08 & -- & -- \\
\hline \multicolumn{4}{|c|}{ 7, Living with father (yes-no) } & & & & & -.18 & .06 & -.19 & .03 & -.09 & -.08 & -- & -- \\
\hline \multicolumn{4}{|c|}{8 , Years living with siblings } & & & & & & .00 & .17 & .25 & .12 & .07 & 4.68 & 1.04 \\
\hline \multicolumn{6}{|c|}{9 , Frequency of conversations with mother } & & & & & .22 & .20 & .13 & .07 & 4.01 & 0.93 \\
\hline \multicolumn{6}{|c|}{10 , Frequency of conversations with father } & & & & & & .15 & .08 & .16 & 3.30 & 1.04 \\
\hline \multicolumn{6}{|c|}{11 , Frequency of conversations with siblings } & & & & & & & -.02 & .06 & 3.50 & 0.98 \\
\hline \multicolumn{6}{|c|}{12 , Amount of time with friends } & & & & & & & & .24 & 3.70 & 1.06 \\
\hline \multicolumn{6}{|c|}{ 13, Having boy/girlfriend (yes-no) } & & & & & & & & -- & -- & -- \\
\hline
\end{tabular}

Note. $r>.13, p<.05, r>.17 ; p<.01$; and $r>.27, p<.001$

Table 2. Hierarchical regression analyses in the full sample $(n=192)$ with Recognition of

Anger Problems as dependent variable

\begin{tabular}{|c|c|c|c|c|c|c|c|c|}
\hline Variables & $\square$ & $t$ & $p$ & $R$ & $R^{2}$ & $\square R^{2}$ & $F$ change & Sig. $F$ \\
\hline Step 1 & & & & .355 & .126 & .126 & 13.60 & .000 \\
\hline Gender & .19 & 2.77 & .006 & & & & & \\
\hline Having boy/girlfriend & -.28 & -4.03 & .000 & & & & & \\
\hline Step 2 & & & & .437 & .191 & .066 & 15.22 & .000 \\
\hline Gender & .15 & 2.24 & .026 & & & & & \\
\hline Having boy/girlfriend & -.28 & -4.23 & .000 & & & & & \\
\hline Trait anger & .25 & 3.90 & .000 & & & & & \\
\hline Step 3 & & & & .484 & .234 & .042 & 10.35 & .002 \\
\hline Gender & .15 & 2.34 & .020 & & & & & \\
\hline Having boy/girlfriend & -.29 & -4.53 & .000 & & & & & \\
\hline Trait anger & .18 & 2.73 & .007 & & & & & \\
\hline Perceptions about & & & & & & & & \\
\hline Others & .21 & 3.21 & .002 & & & & & \\
\hline Step 4(a) & & & & .517 & .267 & .033 & 8.48 & .004 \\
\hline Gender & .16 & 2.56 & .011 & & & & & \\
\hline Having boy/girlfriend & -.28 & -4.54 & .000 & & & & & \\
\hline Trait anger & .21 & 3.10 & .002 & & & & & \\
\hline Perceptions about & & & & & & & & \\
\hline
\end{tabular}




\begin{tabular}{ccccccccc}
\hline others & .20 & 3.01 & .003 & & & & & \\
Importance of family & & & & & & & & \\
Context & .18 & 2.91 & .004 & & & & \\
\hline Step 4(b) & & & & .522 & .272 & .039 & 9.85 & .002 \\
$\quad$ Gender & .10 & 1.63 & .104 & & & & & \\
Having boy/girlfriend & -.27 & -4.30 & .000 & & & & & \\
$\quad$ Trait anger & .17 & 2.66 & .008 & & & & & \\
$\begin{array}{c}\text { Perceptions about } \\
\text { others }\end{array}$ & .24 & 3.62 & .000 & & & & & \\
$\begin{array}{c}\text { Importance of distal } \\
\text { context }\end{array}$ & .20 & 3.13 & .002 & & & & & \\
\hline
\end{tabular}

Note. Degrees of freedom for Step 1, F(2,189); for Step 2, $F(1,188)$; for Step 3, $F(1,187)$; and for Step $4 \mathrm{a}$ and b, $F(1,186)$.

Having a boyfriend/girlfriend was the main predictor (i.e., highest beta weights) to recognize anger problems (Table 2). The inclusion of trait anger in Step two contributed to the recognition of anger problems, accounting for $19.1 \%$ of the variance. Hypotheses 1 and 2 stated, respectively, that perceiving that other individuals have said to the participants they are very irascible contributes to recognizing anger problems, and higher importance attached to messages from others contributes to the recognition. Regressions supported both hypotheses. Perceptions about significant others (Step three), and the importance attached to others, Steps four (a) and (b), significantly increased the explained variance to $23.4,26.7$, and $27.2 \%$, respectively (Table 2 ).

Half of the sample had a boyfriend/girlfriend (46.4\%), and the analyses described (Table 2) did not include the perceptions and importance attached to opinions from boyfriend or girlfriend; nevertheless, they were part of the social context of some participants. Hence, we tested with hierarchical regression analyses whether the recognition of anger problems is also a function of the messages from the boyfriend/girlfriend, and the importance attached to their messages, above and beyond gender and trait anger. Collinearity statistics (tolerance and variance inflation factor) were within acceptable limits (above 0.1 and below 10.0, respectively), indicating the use of regression is appropriate. For the continuous variables, $Z$-scores were used.

Table 3. Hierarchical regression analyses in participants with boyfriend/girlfriend $(n=89)$, with Recognition of Anger Problems as dependent variable

\begin{tabular}{ccccccccc}
\hline Variables & $\square$ & $t$ & $p$ & $R$ & $R^{2}$ & $\square R^{2}$ & $F$ change & Sig. $F$ \\
\hline Step 1 & & & & .370 & .137 & .137 & 13.63 & .000 \\
Gender & .37 & 3.69 & .000 & & & & & \\
Step 2 & & & & .396 & .157 & .020 & 2.01 & .160 \\
Gender & .35 & 3.56 & .001 & & & & & \\
Trait anger & .14 & 1.41 & .160 & & & & & \\
\hline Step 3 & & & & .458 & .210 & .053 & 5.63 & .020 \\
Gender & .37 & 3.80 & .000 & & & & & \\
Trait anger & .06 & 0.66 & .507 & & & & & \\
Perception about & & & & & & & & \\
\hline
\end{tabular}




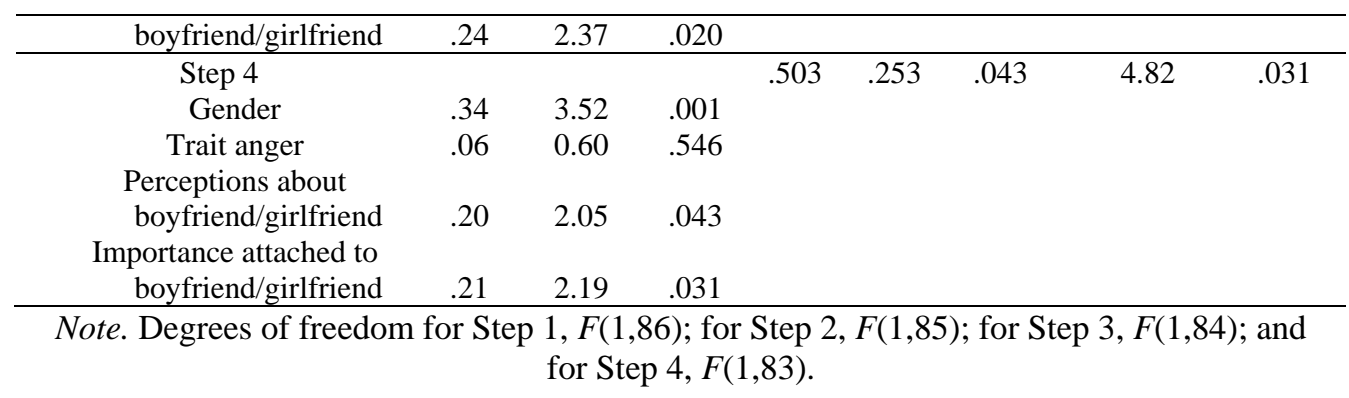

Step one had gender, and Step two trait anger. Step three included perceptions about the frequency in which the boyfriend/girlfriend says to the participant that $\mathrm{s} / \mathrm{he}$ is a very irascible person. Step four considered whether the participants attached importance to messages received from the boyfriend/girlfriend.

As a result, gender was significant in the four Steps (Table 3). Women recognize anger problems more than men. Trait anger was not significant. Nonetheless, regressions supported again Hypotheses 1 and 2. Perceptions about messages from the boyfriend/girlfriend (Step three), and importance attached to such messages (Step four) significantly contributed to the recognition of anger problems, accounting for $21-25 \%$ of the variance.

\section{Discussion}

This research tested two hypotheses of interpersonal nature to recognize anger problems. As a result, people who recognize their anger problems perceived they have received more messages of "You are very irascible," while those who do not recognize them have received these messages less often (Hypothesis 1), and higher importance to others' opinions (i.e., family members and distal context) contributed to higher recognition of anger problems (Hypothesis 2). Both hypotheses were above and beyond other variables. Thus, the interpersonal context (as perceived by the participants) played a role in recognizing anger problems. Anger is an interpersonal emotion (Alcázar, Jiménez, et al., 2015; Averill, 1983), and the interpersonal dimension includes awareness, feedback or possibility to identify anger as a personal problem.

Among the published studies about the recognition of anger problems (Alcázar, Deffenbacher, et al., 2015; Alcázar \& Deffenbacher, 2013; Alcázar, Deffenbacher, Hernández, et al., 2011; Deffenbacher, Filetti, et al., 2003; Deffenbacher, Lynch, et al., 2003), none had included the interpersonal context with regard to recognizing anger problems. However, given that anger is an interpersonal emotion, this research explored the extent to which other individuals might impact on the recognition of anger problems. As expected, other individuals were relevant to perceive anger as a 
personal problem. In addition, when angry people attach importance to messages from others, the result is higher recognition of anger problems. These findings contribute to the field of psychology, in the area of interpersonal relationships to recognize anger problems.

Being female (not male) was associated with recognizing anger problems, while other studies did not find gender effects (Alcázar, Deffenbacher, Hernández, et al., 2011; Alcázar, Deffenbacher, et al., 2015). Moreover, being female and having a significant other contributed significantly to recognize anger problems. Probably, the recognition has an interactional component, where the individual is more open or receptive to messages from a significant other (Furman, 2002; Kassinove \& Tafrate, 2002; Planalp, 1999). As a consequence, this variable merits more study not only to assess if current results replicate, but also to explore the variable further. For example, through interviews to people with a boyfriend/girlfriend, and how the relationship contributes to the recognition of anger problems.

The results might be explained, in part, with an interpersonal perspective on anger and emotion. Excessive anger and the lack of control definitively have detrimental effects in interpersonal relationships (Betch, Prinzie, Dekovic, van den Akker, \& Shiner, 2016; Kennedy, Bolger, \& Shrout, 2002; Klein, Renshaw, \& Curby, 2016; Kuppens, 2005; Suchday \& Larkin, 2001; Tafrate, Kassinove, \& Dundin, 2002). However, significant others may produce two types of results in the recognition of anger problems, which was the focus of the present research. First, it seems that giving feedback or reflecting to the angry individual about his/her emotional reactions may contribute to the recognition of anger problems. Second, the lack of feedback may reduce the possibility to recognize anger as a personal problem. Therefore, the results of the study may empower the social contexts to increase the awareness of angry individuals to notice their anger reactions and negative effects on others.

The results of the study are preliminary, given some limitations that we discuss below. However, assuming that future studies replicate the results with different samples and methods, the findings may lead to some implications at several levels. First, existing models about recognition of a problem and personal change (Miller \& Rollnick, 2013; Prochaska \& Prochaska, 1999) emphasize individual, internal processes. Our findings, however, imply that interpersonal processes may also contribute to recognizing anger as a personal problem. If the results replicate, the social context should receive more attention to better understand the presence and lack of recognition of anger problems. Second, for anger treatments, the implication is to assess potential clients in terms of perceptions about their interpersonal context, among other aspects. Moreover, such context and 
significant others might serve as a motivation to get involved in anger reduction. Third, the findings have social-practical implications. Specifically, if it is desired that angry individuals recognize their anger problems, it becomes relevant that social contexts (e.g., friends, family members) explicitly communicate to these individuals about how they react. The social context might work as a "mirror" for the angry individual to identify emotional/behavioral reactions.

The results of the study should be considered in the frame of some limitations and alternative explanations. First, people who belong to the social contexts were not directly assessed. We did not validate the participants' perceptions with information from their contexts. Probably, participants are under or over reporting what others say about the participants' anger. Therefore, this research cannot state a conclusion about the opinions from significant others. At most, we can conclude only that based on participants' perceptions, others contribute to the recognition of anger problems. However, the study of perceptions is not necessarily wrong (Connolly, Kavanagh, \& Viswesvaran, 2007). For example, reports of high trait anger from self and significant others are correlated (Ilie, Penney, Ispas, \& Iliescu, 2012), and spouse and self-ratings on anger-hostility also correlate (Costa \& McCrae, 1992), suggesting overlap on interpersonal anger perception. This is consistent with conceiving anger as an interpersonal emotion (Alcázar, Jiménez, et al., 2015; Averill, 1983).

Second, the first hypothesis may have an alternative explanation. It is not that individuals with higher trait anger perceived they have received more messages of "You are very irascible." Rather, individuals with higher trait anger may pay more attention to anger-related messages (Eckhardt \& Cohen, 1997), which leads to higher recognition. It is the attentional bias to messages from others what produces the recognition of anger problems, not the messages from the others. Although attentional bias exists in individuals with high trait anger (Eckhardt \& Cohen, 1997), future research should study if such bias leads to recognition of anger problems.

Third, the validity of the Involvement with Significant Others Scale is questionable. The scale was designed for this research, without revising validity before using it. However, this study might be the first step toward the validation of the scale to use it in future research. At this moment, the scale only has face validity. Therefore, conclusions derived from this measure are only preliminary, although results from this measure are consistent with a wider literature on anger research (Deffenbacher, Lynch, et al., 2003). Specifically, angry drivers experience this emotion regardless of the number of miles they drive, indicating that the time of exposure to driving does not determine anger frequency (Deffenbacher, Lynch, et al., 2003). This research found the time spent with others (i.e., exposure to 
relationships) does not determine the frequency of the message "You are very irascible." Results are more interpretable in terms of the person's anger proneness, which results in the credibility of the message of being irascible.

Fourth, this study relied on self-reports, which may not correspond to actual feelings and behaviors. Nevertheless, this strategy is appropriate to assess internal states like anger (Bradburn, Sudman, \& Wansink, 2004; Baron \& Richardson, 1994). Fifth, we used the upper quartile of high trait anger as the only criteria to detect individuals with anger problems. Such procedure is valid and common (DiGiuseppe \& Tafrate, 2003), but additional criteria may yield a more solid distinction of anger problems; for example, assessing the extent to which anger impedes individual and social functioning in everyday life, and the damage caused to relationships with loved ones. Sixth, this research took for granted that high trait anger means anger problems; however, anger might be appropriate for some individuals. For example, if the person belongs to a negative, hostile environment, anger might be a natural or appropriate reaction. In these cases, anger might be a natural consequence or a solution, not a problem (Englander, 2007; Lopez \& Thurman, 1993).

In summary, the inclusion of interpersonal variables provided new insights associated with the presence and lack of recognition of anger problems. Because anger is an interpersonal emotion, this line of research may lead to additional answers and intervention proposals that include the social context to increase and promote awareness of anger as a personal problem.

\section{References:}

1. Alcázar, R. J., \& Deffenbacher, J. L. (2013). High trait anger Mexican youth: Characteristics, parental anger, and counseling needs. The Spanish Journal of Psychology, 16, 1-10. http://dx.doi.org/10.1017/sjp.2013.89

2. Alcázar, R. J., Deffenbacher, J. L., \& Byrne, Z. S. (2011). Assessing the factor structure of the anger expression inventory (ML-STAXI) in a Mexican sample. International Journal of Psychology and Psychological Therapy, 11, 307-318.

3. Alcázar, R. J., Deffenbacher, J. L., Hernández-Guzmán, L., \& Jurado-Cárdenas, S. (2015). High and low trait anger, angry thoughts, and the recognition of anger problems. The Spanish Journal of Psychology, 18, 1-9. http://dx.doi.org/10.1017/sjp.2015.84

4. Alcázar, R. J., Deffenbacher, J. L., Hernández-Guzmán, L., \& Wilson, G. I. (2011). High and low trait anger, and the recognition of anger problems. The Spanish Journal of Psychology, 14, 851-858. http://dx.doi.org/10.5209/rev_SJOP.2011.v14.n2.32 
5. Alcázar-Olán, R. J., Jiménez Cisneros, R., Mena Macari, M., Ponce de León Paredes, M., \& Gutiérrez Ramos, O. (2015). Qué hace enojar a estudiantes universitarios y qué piensan cuando se enojan [What makes university students angry and what do they think when they are angry]. Psicología y Salud, 25, 123-131.

6. Archer, J. (2004). Sex differences in aggression in real-world settings: A meta-analytic review. Review of General Psychology, 8, 291-322. http://dx.doi.org/10.1037/1089-2680.8.4.291

7. Averill, J. R. (1983). Studies on anger and aggression. American Psychologist, 38, 1145-1160. http://dx.doi.org/10.1037/0003066X.38.11.1145

8. Baron, R. A., \& Richardson, D. R. (1994). Human aggression (second edition). New York: Plenum Press.

9. Bartz, A. E., Blume, N. E., \& Rose, J. (1996). Gender differences in self-report measures of anger: The role of social desirability and negative affect. Journal of Social Behavior and Personality, 11 (5), 241-253.

10. Betch, A. I., Prinzie, P., Dekovic, M., van den Akker, A. L., \& Shiner, R. L. (2016). Child personality facets and overreactive parenting as predictors of aggression and rule-breaking trajectories from childhood to adolescence. Development and Psychopathology, 28, 399-413. http://dx.doi.org/10.1017/S0954579415000577

11. Bradburn, N., Sudman, S., \& Wansink, B. (2004). Asking Questions. San Francisco, CA: Jossey-Bass.

12. Brotman, M. A., Kircanski, K., Stringaris, A., Pine, D. S., \& Leibenluft, E. (2017). Irritability in youths: A translational model. American Journal of Psychiatry, 174, 520-532. http://dx.doi.org/10.1176/appi.ajp.2016.16070839

13. Connolly, J. J., Kavanagh, E. J., \& Viswesvaran, C. (2007). The convergent validity between self and observer ratings of personality: A meta-analytic review. International Journal of Selection and Assessment, 15, 110-117. http://dx.doi.org/10.1111/j.14682389.2007.00371.x

14. Costa, P. T., \& McCrae, R. R. (1992). Revised NEO Personality Inventory (NEO-PI-R) and Neo Five-Factor Inventory (NEO-FFI): Professional Manual. Odessa, FL: Psychological Assessment Resources.

15. Deffenbacher, J. L. (1993). General anger: Characteristics and clinical implications. Psicología Conductual, 1 (1), 49-67.

16. Deffenbacher, J. L. (2009). Angry drivers: Characteristics and clinical interventions. Revista Mexicana de Psicología, 26, 5-16. 
17. Deffenbacher, J. L., Filetti, L. B., Richards, T. L., Lynch, R. S., \& Oetting, E. R. (2003). Characteristics of two groups of angry drivers. Journal of Counseling Psychology, 50, 123-132. http://dx.doi.org/10.1037/0022-0167.50.2.123

18. Deffenbacher, J. L., Lynch, R. S., Filetti, L. B., Dahlen, E. R., \& Oetting, E. R. (2003). Anger, aggression, risky behavior, and crashrelated outcomes in three groups of drivers. Behaviour Research and Therapy, 41, 333-349. http://dx.doi.org/10.1016/S00057967(02)00014-1

19. Deffenbacher, J. L., Oetting, E. R., Thwaites, G. A., Lynch, R. S., Baker, D. A., Stark, R. S.,.. Eiswerth-Cox, L. (1996). State-trait anger theory and the utility of the trait anger scale. Journal of Counseling Psychology, 43, 131-148. http://dx.doi.org/10.1037/00220167.43.2.131

20. Deffenbacher, J. L., Richards, T. L., Filetti, L., B., \& Lynch, R. S. (2005). Angry drivers: A test of state-trait theory. Violence and Victims, 20, 455-469. http://dx.doi.org/10.1891/vivi.2005.20.4.455

21. DiGiuseppe, R., \& Tafrate, R. C. (2003). Anger treatment for adults: A meta-analytic review. Clinical Psychology: Science and Practice, 10, 70-84. http://dx.doi.org/10.1093/clipsy.10.1.70

22. Eckhardt, C. I., \& Cohen, D. J. (1997). Attention to anger-relevant and irrelevant stimuli following naturalistic insult. Personality and Individual Differences, 23, 619-629. http://dx.doi.org/10.1016/S0191-8869(97)00074-3

23. Englander, E. K. (2007). Understanding violence (third edition). New York: Psychology Press, Taylor and Francis Group.

24. Fernandez, E., \& Johnson, S. L. (2016). Anger in psychological disorders: Prevalence, presentation, etiology and prognostic implications. Clinical Psychology Review, 46, 124-135. http://dx.doi.org/10.1016/j.cpr.2016.04.012

25. Furman, W. (2002). The emerging field of adolescent romantic relationships. Current Directions in Psychological Science, 11, 177180. http://dx.doi.org/10.1111/1467-8721.00195

26. Hair, J. F., Anderson, R. E., Tathan, R. L., \& Black, W. C. (1999). Análisis Multivariante (5a ed.). Madrid: Prentice Hall.

27. Howells, K. \& Day, A. (2003). Readiness for anger management: Clinical and theoretical issues. Clinical Psychology Review, 23, 319337. http://dx.doi.org/10.1016/S0272-7358(02)00228-3

28. Ilie, A., Penney, L. M., Ispas, D., \& Iliescu, D. (2012). The role of trait anger in the relationship between stressors and counterproductive work behaviors: Convergent findings from multiple studies and methodologies. Applied Psychology: An 
International Review, 61, 415-436. http://dx.doi.org/10.1111/j.14640597.2011.00476.x

29. Kassinove, H., \& Tafrate, R. C. (2002). Anger management: The complete guidebook for practitioners. California: Impact Publishers Inc.

30. Kassinove, H., \& Tafrate, R. C. (2006). Anger-related disorders: Basic issues, models, and diagnostic considerations. In E. L. Feindler (Ed.), Anger-Related Disorders: A Practitioner's Guide to Comparative Treatments (pp. 1-27). New York: Springer.

31. Kennedy, J. K., Bolger, N., \& Shrout, P. E. (2002). Witnessing interparental psychological aggression in childhood: Implications for daily conflict in adult intimate relationships. Journal of Personality, 70, 1051-1077. http://dx.doi.org/10.1111/1467-6494.05031

32. Klein, S. R., Renshaw, K. D., \& Curby, T. W. (2016). Emotion regulation and perceptions of hostile and constructive criticism in romantic relationships. Behavior Therapy, 47, 143-154. http://dx.doi.org/10.1016/j.beth.2015.10.007

33. Kuppens, P. (2005). Interpersonal determinants of trait anger: low agreeableness, perceived low social esteem, and the amplifying role of the importance attached to social relationships. Personality and Individual Differences, $\quad 38, \quad$ 13-23. http://dx.doi.org/10.1016/j.paid.2004.03.006

34. Kuppens, P., Mechelen, I. V., \& Rijmen, F. (2008). Toward disentangling sources of individual differences in appraisal and anger. Journal of Personality, 76, 969-1000. http://dx.doi.org/10.1111/j.1467-6494.2008.00511.x

35. Lopez, F. G., \& Thurman, C. W. (1993). High-trait and low-trait angry college students: A comparison of family environments. Journal of Counseling \& Development, 71, 524-527. http://dx.doi.org/10.1002/j.1556-6676.1993.tb02235.x

36. McDermut, W., Fuller, J. R., DiGiuseppe, R., Chelminski, I., \& Zimmerman, M. (2009). Trait anger and Axis I comorbidity: Implications for rational emotive behavior therapy. Journal of Rational Emotive \& Cognitive Behavior Therapy, 27, 79-82. http://dx.doi.org/10.1007/s10942-009-0092-2

37. Miller, W. R., \& Rollnick, S. (2013). Motivational interviewing: Helping people change ( $3^{\text {rd }}$ ed.). New York: Guilford

38. Miller, W. R., \& Tonigan, J. S. (1996). Assessing drinkers' motivation for change: The stages of change readiness and treatment eagerness scale (SOCRATES). Psychology of Addictive Behaviors, 10, 81-89. http://dx.doi.org/10.1037/0893-164X.10.2.81 
39. Owen, J. M. (2011). Transdiagnostic cognitive processes in high trait anger. Clinical Psychology Review, 31, 193-202. http://dx.doi.org/10.1016/j.cpr.2010.10.003

40. Planalp, S. (1999). Communicating emotions: Social, moral, and cultural processes. Cambridge: Cambridge University Press.

41. Prochaska, J. O. \& Prochaska, J. M. (1999). Why don't continents move? Why don't people change? Journal of Psychotherapy Integration, 9, 83-102. http://dx.doi.org/10.1023/A:1023210911909

42. Quinn, C. A., Rollock, D., \& Vrana, S. R. (2014). A test of Spielberger's state-trait theory of anger with adolescents: Five hypotheses. Emotion, 14, 74-84. http://dx.doi.org/10.1037/a0034031

43. Smith, C. A., Haynes, K. N., Lazarus, R. S., \& Pope, L. K. (1993). In search of the "hot" cognitions: Attributions, appraisals, and their relation to emotion. Journal of Personality and Social Psychology, 65, 916-929. http://dx.doi.org/10.1023/A:1019876601693

44. Spielberger, C. D. (1999). Manual for the state-trait anger expression inventory-revised. Orlando, Fl: Psychological Assessment Resources.

45. Suchday, S., \& Larkin, K. T. (2001). Biobehavioral responses to interpersonal conflict during anger expression among anger-in and anger-out men. Annals of Behavioral Medicine, 23, 282-290. http://dx.doi.org/10.1207/S15324796ABM2304_7

46. Tafrate, R. C., Kassinove, H., \& Dundin, L. (2002). Anger episodes in high- and low-trait anger community adults. Journal of Clinical Psychology, 58, 1573-1590. http://dx.doi.org/10.1002/jclp.10076

47. Wang, X., Yang, L., Yang, J., Wang, P., \& Lei, L. (2017). Trait anger and cyberbullying among young adults: A moderated mediation model of moral disengagement and moral identity. Computers in Human Behavior, 73, 519-526. http://dx.doi.org/10.1016/j.chb.2017.03.073

48. Wilkowski, B. M., \& Robinson, M. D. (2010). The anatomy of anger: An integrative cognitive model of trait anger and reactive aggression. Journal of Personality, 78, 9-38. http://dx.doi.org/10.1111/j.14676494.2009.00607.x 